\title{
Erratum to: Induction of morphine-6-glucuronide synthesis by heroin self-administration in the rat
}

\author{
Maria Meringolo • Valentina Brusadin • \\ Maria T. De Luca • Christian Montanari • \\ Letizia Antonilli • Paolo Nencini • Aldo Badiani
}

Published online: 31 March 2012

(C) Springer-Verlag 2012

\section{Erratum to: Psychopharmacology}

\section{DOI 10.1007/s00213-011-2534-7}

The name of Mr. Montanari was incorreclty indicated as "Montanari CL" whereas the correct name is "Montanari C".

The online version of the original article can be found at http://dx.doi.org/ 10.1007/s00213-011-2534-7.

M. Meringolo $\cdot$ M. T. De Luca $\cdot$ C. Montanari $\cdot$ L. Antonilli $\cdot$

P. Nencini $\cdot$ A. Badiani $(\bowtie)$

Department of Physiology and Pharmacology Vittorio Erspamer,

Sapienza University of Rome,

Rome, Italy

e-mail: aldo.badiani@uniroma1.it

P. Nencini $\cdot$ A. Badiani

Center for Research in Neurobiology Daniel Bovet,

Sapienza University of Rome,

Rome, Italy

V. Brusadin · L. Antonilli · P. Nencini · A. Badiani

Drug Addiction and Clinical Pharmacology Unit, University

Hospital Policlinico Umberto I, Sapienza University of Rome,

Rome, Italy 